\title{
Clustering economies based on multiple criteria decision making techniques
}

\author{
Mansour Momeni ${ }^{\mathrm{a}}$, Mohammad Mehrabioun Mohammadi ${ }^{\mathrm{a}}$, Mohammad Hassan Maleki $^{\mathrm{a}}$ and \\ Mohammad Ali Afshari ${ }^{\mathrm{b}^{*}}$
}

${ }^{a}$ Department of Management, University of Tehran, Tehran, Iran

${ }^{b}$ Department of Management, Kar University, Qazvin, Iran

\begin{tabular}{l}
\hline A R T I C L E I N F O \\
\hline Article history: \\
Received April 15, 2011 \\
Received in Revised form \\
May, 30, 2011 \\
Accepted 31 May 2011 \\
Available online \\
14 June 2011 \\
\hline Keywords: \\
GDP growth \\
Clustering \\
MCDM \\
AHP \\
K-median
\end{tabular}
A B S T R A C T

\begin{abstract}
One of the primary concerns on many countries is to determine different important factors affecting economic growth. In this paper, we study some factors such as unemployment rate, inflation ratio, population growth, average annual income, etc to cluster different countries. The proposed model of this paper uses analytical hierarchy process (AHP) to prioritize the criteria and then uses a K-mean technique to cluster 59 countries based on the ranked criteria into four groups. The first group includes countries with high standards such as Germany and Japan. In the second cluster, there are some developing countries with relatively good economic growth such as Saudi Arabia and Iran. The third cluster belongs to countries with faster rates of growth compared with the countries located in the second group such as China, India and Mexico. Finally, the fourth cluster includes countries with relatively very low rates of growth such as Jordan, Mali, Niger, etc.
\end{abstract}

\section{Introduction}

One of the primary concerns on many governmental levels is to learn more about the important factors on economic growth. In fact, there are normally various elements playing crucial role on monitoring economic growth such as unemployment rate, inflation rate, people's average income, etc. There are also various techniques on gathering conflicting criteria in an integrated model for measuring the relative growth of countries. There are, however, some studies, which only focus on one single criteria such as ISO certificate for clustering countries. Franceschini et al. (2010), for instance, used ISO 9000-certification diffusion for clustering European countries.

Aiginger (2005) compared the impact of labour market regulation to some macroeconomic policies such as fiscal policy, macroeconomic cost, monetary policy, management for investment into future growth and reported that regulation could impact the economic growth but it is not an easy task to demonstrate its effects. The results also indicated that the impact of macroeconomic policy can be

* Corresponding author. Tel: +989382029618

E-mail addresses: mohamadaliafshari@yahoo.com (M. A. Afshari) 
explained first by the more growth oriented monetary and fiscal policy in the US and the success of some European countries in absorbing private and public expenditures in line with productivity and tax revenues. However, there are some issues for boosting investment into future growth such as encouraging research, education and technology diffusion.

There are some other studies, which focus on the relationship between countries' government size and the shares of taxes in GDP as important factors for economic determinants (Zagler \& Durnecker, 2003; Nijkamp \& Poot, 2003). Productivity is another important factor in economic growth of any country. In fact, a more productive economy could boost labour market and GDP growth (Nicoletti \& Scarpetta, 2002). Recently, there are other studies suggesting that we need to consider some new important issues such as global warming, healthcare, etc as part of economic growth of countries (Floyd, 2011). He argues that growth is a measure of output and as it increases, we assume that everyone will feel better off in a particular society, there is an increase on government spending and people have better income to consume and invest more. However, we have some societies where the average income increases but at the same time, we see the general health care deteriorating for different reasons such as air pollution.

As we can observe from the literature, comparing different economies is a complex decision making problem where there are different conflicting criteria must be considered. Therefore, we need to use different multi criteria decision making (MCDM) techniques to consider different alternatives based on various criteria. During the past few decades, there have been tremendous MCDM techniques have proposed for comparing various alternatives. The first group includes methods that gather decision makers' feedback for ranking alternatives while the second group performs the ranking solely based on some input data without involvement of any DM. Analytical hierarchy process (AHP) is among the MCDM methods grouped in the first category. This method performs a pairwise comparison among various alternatives based on different criteria, which makes it easy for DM to make a decision (Saaty, 1994, 1996). There are other techniques, which belong to the second group such as technique for order preference by similarity to ideal solution (TOPSIS). The idea of this method is to that chosen alternative must be as close as possible to the ideal solution and as far as possible from the negative-ideal solution. The ideal output solution is formed as a combination of the best performance values in terms of a matrix by any alternative for each attribute. Proximity to each

of these performance criteria is computed based on Euclidean norm and attributes could be weighted by another MCDM method such as AHP (Yoon \& Hwang, 1980).

In this paper, we propose some MCDM methods for clustering different countries based on various attributes. We first discuss the most important criteria affecting the economic growth such as inflation, unemployment rate, etc and then rank them based on AHP method. The raking alternative is then used for clustering countries. This paper is organized as follows. We first discuss the important

factors and, using the AHP technique ranks them in section 2. Section 3 presents the clustering scheme and finally concluding remarks are given in the last section to summarize the contribution of the paper.

\section{Factors influencing economic growth}

In this section, we study different important factors influencing economy either positively or negatively.

\subsection{Annual income}

Annual income is one of good indication for the designation of improved societies from unimproved societies. In fact, one of important characteristic of underdeveloped countries is the lack of annual income, which is directly resulted from the lack of national impure production level. As the average 
income of a country's population increases there will be more spending on that country which result to higher production and growth on economy.

\subsection{Population growth}

In order to study the impact of population growth on economy we need to look at the age structure of a society as well. In fact, a society with significant number of children may face different challenges on economy since government needs to spend significant amount of money for education and healthcare hoping that these people would come to economy and create value in future. On the other hand, when a big portion of a population suddenly comes to job market, economy may not necessarily have the potential to provide job opportunity for them. Unfortunately, many developing countries suffer from having young generation where economy cannot create enough job opportunity for them. Table 1 shows that rate of population growth is gradually reduced along with process of countries' development and improvement.

\section{Table 1}

Rate of population growth in selected countries (estimation for 1992-2000)

\begin{tabular}{lclclc}
\hline Industrial improved countries & Improving countries & \multicolumn{3}{l}{ A little improved countries } \\
\hline Country & Rate of growth & Country & Rate of growth & Country & Rate of growth \\
\hline USA & 0.9 & South Korea & 1.00 & Yemen & 3.9 \\
Japan & 0.2 & Argentina & 1.2 & Nigeria & 3.4 \\
France & 0.4 & Brazil & 1.6 & Syria & 3.4 \\
German & 0.2 & Thailand & 1.0 & Nicaragua & 3.4 \\
Belgium & 0.3 & Indonesia & 1.5 & Tanzania & 2.9 \\
Italy & 0.0 & China & 1.0 & Pakistan & 2.8 \\
England & 0.3 & Iran & 2.2 & Kenya & 3.1 \\
Denmark & 0.1 & Turkey & 1.9 & Libya & 3.4 \\
Spain & 0.1 & Malaysia & 2.2 & Laos & 2.9 \\
\hline
\end{tabular}

\subsection{Axial knowledge}

According to Drucker (1993), 21st century is the knowledge-based economy. In this economy, thinking assets and humane capitals are accounted as the most important organizational assets; also potential success of organizations are rooted in their thinking capacities.

\subsection{Diversification of economy}

A country with diversified sources of income could provide better sustainable growth whereas an economy with one simple source of income, e.g. exporting oil, could have fluctuating GDP growth.

\subsection{Unemployment}

Unemployment is one of unsuitable phenomenon that has many negative economic-social results and it can cause severe problems on countries infrastructure. Economists divide unemployment into three groups of frictional unemployment, structural unemployment and periodic unemployment.

\subsection{Inflation}

Inflation is a situation where prices are gradually and continuously hiked in the public level. An increase on purchasing items increases the cost of production and reduces customers' buying power. As a result, people tend to reduce their spending which means a decline on economy growth. 
In summary, we believe these components play important role on economy and could be used for clustering different countries. Next section we explain MCDM techniques to rank these issues and to cluster the countries.

\section{The proposed MCDM clustering technique}

As we explained earlier, we intend to rank six criteria based on decision makers' feedback. Therefore, we use AHP method for ranking these criteria. In order to have wise ranking results we have chosen four experts who have good background knowledge on the impact of these factors. The AHP method uses preference numbers between one to nine and geometric mean is implemented to find overall rating for each pair of comparison. Table 2 summarizes the results of our survey for pairwise comparisons and the ranking of six alternatives.

Table 2

The summary of pairwise comparison of six attributes

\begin{tabular}{lccccccc}
\multicolumn{1}{c}{ Index } & $\begin{array}{c}\text { Annual } \\
\text { income }\end{array}$ & $\begin{array}{c}\text { Rate of } \\
\text { population }\end{array}$ & $\begin{array}{c}\text { Knowledge } \\
\text { care }\end{array}$ & $\begin{array}{c}\text { Diversificatio } \\
\text { n of economy }\end{array}$ & $\begin{array}{c}\text { Unemployment } \\
\text { rate }\end{array}$ & $\begin{array}{c}\text { Inflation } \\
\text { rate }\end{array}$ & Rank \\
\hline Annual income & 1 & 0.483 & 0.144 & 0.156 & 1 & 2.449 & 0.07 \\
Rate of population & & 1 & 0.319 & 0.309 & 2.632 & 3.761 & 0.141 \\
Knowledge care & & & 1 & 1.682 & 3.663 & 4.356 & 0.355 \\
Diversification of economy & & & & 1 & 4.229 & 5.009 & 0.307 \\
Unemployment rate & & & & & 1 & 2.213 & 0.079 \\
Inflation rate & & & & & & & 0.048 \\
\hline
\end{tabular}

As we can observe from Table 2, knowledge is the most important factor and it has the maximum point among these factors and a diversified economy is the second most important for economic growth. These two factors account over $65 \%$ of the most important influencing factors on growth of economy and the other three factors of rate of population, annual income and inflation rate are considered as the secondary issues for economic growth. We have also considered the consistency ratio, which meet the minimum requirement.

Next step is to find suitable clustering scheme to separate countries based on six alternatives. We have used K-median clustering method (Jain \& Dubes, 1981). In statistics, k-medians clustering is a kind of k-means clustering where instead of calculating the mean for each cluster to determine its centroid, one calculates the median in order to minimize error over all clusters with respect to the 1norm distance metric, as opposed to the square of the 2-norm distance metric. Table 3 summarizes the results of the initial clustering for the implementation of our k-median clustering method.

Table 3

Initial Cluster Centers

\begin{tabular}{lcccc}
\hline & \multicolumn{3}{c}{ Cluster } \\
Criteria & 1 & 2 & 3 & 4 \\
\hline Annual income & .0249653 & .0019289 & .0012571 & .0002735 \\
Rate of population & .0033030 & .0088969 & .0006926 & .0158226 \\
Knowledge care & .0191026 & .0038205 & .0152821 & .0038205 \\
Diversification of economy & .0161988 & .0032398 & .0129591 & .0032398 \\
Unemployment rate & .0020552 & .0039702 & .0042038 & .0163481 \\
Inflation rate & .0005475 & .0123196 & .0020533 & .0085553 \\
\hline
\end{tabular}

A Convergence achieved due to no or small change in cluster centers. The maximum absolute coordinate change for any center is .000 in less than three iterations. The minimum distance between initial centers is .015. We have used the clustering for 59 different countries. The k-median clustering assigns each country to one of four clusters and the summary of the clustering are given in Table 4. 
Table 4

Cluster membership

\begin{tabular}{cccccccc}
\hline Case Number & country name & Cluster & Distance & Case Number & country name & Cluster & Distance \\
\hline 1 & Niger & 4 & .007 & 31 & Argentina & 3 & .005 \\
2 & Jordon & 4 & .005 & 32 & Turkey & 3 & .005 \\
3 & Mali & 4 & .003 & 33 & Uruguay & 3 & .005 \\
4 & Yemen & 4 & .006 & 34 & Thailand & 3 & .004 \\
5 & Kenya & 4 & .007 & 35 & Mexico & 3 & .004 \\
6 & Lebanon & 2 & .007 & 36 & Lebanon & 3 & .005 \\
7 & Syria & 2 & .005 & 37 & Australia & 1 & .006 \\
8 & Tanzania & 2 & .005 & 38 & Chile & 3 & .003 \\
9 & Senegal & 2 & .006 & 39 & United S & 1 & .004 \\
10 & Saudi Arabia & 2 & .006 & 40 & Canada & 1 & .004 \\
11 & Kuwait & 2 & .009 & 41 & Spain & 3 & .004 \\
12 & Sudan & 2 & .005 & 42 & Norway & 1 & .008 \\
13 & Mauritania & 4 & .005 & 43 & France & 1 & .003 \\
14 & Oman & 2 & .005 & 44 & United K & 1 & .002 \\
15 & Honduras & 2 & .004 & 45 & Serbia & 3 & .006 \\
16 & Pakistan & 2 & .003 & 46 & Greece & 3 & .006 \\
17 & Venezuela & 2 & .008 & 47 & Belgium & 3 & .004 \\
18 & Paraguay & 2 & .003 & 48 & Italy & 1 & .005 \\
19 & South Korea & 3 & .007 & 49 & Denmark & 1 & .005 \\
20 & Ireland & 1 & .007 & 50 & China & 3 & .004 \\
21 & Philippi & 2 & .005 & 51 & Japan & 1 & .004 \\
22 & Malaysia & 3 & .008 & 52 & Slovakia & 3 & .004 \\
23 & South Africa & 3 & .008 & 53 & Germany & 1 & .005 \\
24 & Egypt & 2 & .004 & 54 & Brazil & 3 & .005 \\
25 & Tajikistan & 2 & .003 & 55 & Poland & 3 & .006 \\
26 & Costa Rica & 2 & .004 & 56 & Armenia & 3 & .007 \\
27 & India & 3 & .006 & 57 & Russia & 3 & .006 \\
28 & Uzbekistan & 2 & .004 & 58 & Ukraine & 3 & .009 \\
29 & Iran & 2 & .010 & 59 & Bulgaria & 3 & .007 \\
30 & Vietnam & 2 & .005 & & & & \\
\hline
\end{tabular}

The implementation of the final k-median factor needs to verify the final cluster centers to be within specified limit. Table 5 summarizes the results of our implementation.

Table 5

Final cluster centers

\begin{tabular}{lcccc}
\hline \multirow{2}{*}{ Attributes } & \multicolumn{4}{c}{ Cluster } \\
\cline { 2 - 5 } & 1 & 2 & 3 & 4 \\
\hline Annual income & .0166238 & .0015519 & .0021586 & .0003343 \\
Rate of population & .0031432 & .0098782 & .0025618 & .0156361 \\
knowledge care & .0180606 & .0064345 & .0107971 & .0044573 \\
Diversification of economy & .0153153 & .0069911 & .0101419 & .0032398 \\
Unemployment rate & .0025562 & .0047790 & .0039601 & .0118329 \\
inflation rate & .0012693 & .0054249 & .0034935 & .0039354 \\
\hline
\end{tabular}

As we can observe from Table 4, there are eleven countries of Germany, Japan, Denmark, Italy, Norway, France, United Kingdom Canada, US, Australia, Ireland located in the first cluster. There also 19 countries located in the second cluster which are Uzbekistan, Iran, Vietnam, Tajikistan, Costa Rica, Egypt, Philippi, Paraguay, Venezuela, Pakistan, Honduras, Oman, Sudan, Kuwait, Saudi Arabia, Senegal, Tanzania, Syria, Lebanon. The third cluster includes 23 countries, which are South Korea, Malaysia, South Africa, India, Argentina, Turkey, Uruguay, Thailand, Mexico, Lebanon, Chile, Spain, Serbia, Greece, Belgium, China, Slovakia, Brazil, Poland, Armenia, Russia, Ukraine 
and Bulgaria. Finally, six countries are assigned to the fourth cluster, which are Niger, Jordon, Mali, Yemen, Kenya and Mauritania. There are also two countries, which are missing from our results.

As we can observe, the first group includes countries with high standards such as Germany and Japan. In the second cluster, there are some developing countries with relatively good economic growth such as Saudi Arabia and Iran. The third cluster belongs to countries with faster rates of growth compared with the countries located in the second group such as China, India and Mexico. Finally, the fourth cluster includes countries with relatively very low rates of growth such as Jordan, Mali, Niger, etc. The results indicate that there are some non-financial factors influencing the economy of countries such as knowledge and education. In fact, having a good infrastructure specially on the basis of knowledge could help many countries reach better economic growth.

\section{Conclusion}

In this paper, we have performed an empirical study on important factors influencing different countries' economy. We have explained that one of the primary concerns on many countries is to determine different important factors affecting economic growth. We have studied different important factors such as unemployment rate, inflation ratio, population growth, average annual income, etc and we have clustered different countries using k-median technique. The proposed model of this paper used analytical hierarchy procedure (AHP) to prioritize the criteria and then used a K-mean technique to cluster countries based on the ranked criteria into four groups. The first group included countries with high standards such as Germany and Japan. In the second cluster, there were some developing countries with relatively good economic growth such as Saudi Arabia and Iran. The third cluster belonged to countries with faster rates of growth compared with the countries located in the second group such as China, India and Mexico. Finally, the fourth cluster included countries with relatively very low rates of growth such as Jordan, Mali, Niger, etc.

The present study of this paper could be extended using some more sophisticated MCDM techniques to rank alternatives such as fuzzy TOPSIS, ELECTRE, etc and we leave it for interested readers to continue this research work.

\section{References}

Aiginger, K. (2005). Labour market reforms and economic growth - the European experience in the 1990s. Journal of Economic Studies, 32(6), 540-573.

Drucker, P.F. (1993). The Ecological Vision. Reflections on the American Condition. Transaction Publishers, New Brunswick, NJ.

Floyd, D. (2011). Do traditional measures of economic performance really satisfy the needs of citizens for a better society?. International Journal of Social Economics, 38(3), 218-223.

Franceschini, F., Galetto, M., Maisano, D., \& Mastrogiacomo, L. (2010). Clustering of European countries based on ISO 9000 certification diffusion. International Journal of Quality \& Reliability Management, 27(5), 558-575.

Jain, A. K., \& Dubes, R. C. (1981). Algorithms for Clustering Data. Prentice-Hall.

Nijkamp, P., \& Poot, J. (2003), Meta-analysis of the effect of fiscal policies on long-run growth. European Journal of Political Economy, 20, 91-124.

Nicoletti, G., \& Scarpetta, St. (2002). Regulation, Productivity and Growth: OECD Evidence, OECD, Paris.

Saaty, T. L. (1994). How to make a decision: the analytic hierarchy process. Interface, 24(6), 19-43.

Saaty, T.L. (1996). Multicriteria Decision Making, The Analytic Hierarchy Process, RWS Publications, 4922 Ellsworth Avenue, Pittsburgh, PA, 15213.

Yoon K., \& Hwang, C.L. (1980). Multiple Attribute Decision Making Methods and Applications. A State of the Art Survey, Springer Verlag, Berlin.

Zagler, M., \& Durnecker, G. (2003). Fiscal policies and economic growth. Journal of Economic Surveys, 17(3), 397-418. 